\title{
Clinical effects of an oral supplement rich in antioxidants on skin radiance in women
}

\author{
Marion Dumoulin \\ David Gaudout \\ Benoit Lemaire \\ Activ'Inside, Libourne, France
}

Correspondence: Marion Dumoulin Activ'Inside, Espace Legendre, 33 rue Max Linder, 33500 Libourne, France Tel +33 $53554 \mid 560$

Email m.dumoulin@activinside.com
This article was published in the following Dove Press journal:

Clinical, Cosmetic and Investigational Dermatology

18 October 2016

Number of times this article has been viewed

Background: Environmental factors impact the skin aging resulting in decrease of skin radiance. Nutrition and particularly antioxidants could help to fight against skin degradation.

Objective: The aim of this study was to evaluate the effects of an oral supplement rich in specific antioxidants, SkinAx ${ }^{2 \mathrm{TM}}$, on the improvement of the skin radiance in women.

Methods: The open-label clinical study enrolled 35 women, aged 40-70, with facial dull complexion. Subjects were supplemented orally with a daily dosage of $150 \mathrm{mg}$ of an antioxidant-rich formulation containing superoxide dismutase-rich melon concentrate, grape seed extract rich in monomers of flavanols, vitamin $\mathrm{C}$, and zinc for 8 weeks. Each subject served as her own control. The C.L.B.T. ${ }^{\mathrm{TM}}$ test has been used to evaluate facial skin coloring (C), luminosity (L), brightness (B), and transparency (T) involved in skin radiance. Facial skin imperfections have been assessed by clinical assessment. Firmness has been evaluated by clinical assessment and cutometer measurement. Finally, an auto-questionnaire has been carried out in order to evaluate the satisfaction of the subjects concerning different parameters involved in skin radiance and the global efficacy of the supplement.

Results: Skin "red pink" and "olive" colors were significantly improved after supplementation $(P<0.0001)$. Luminosity was increased by $25.9 \%(P<0.0001)$ whereas brightness and transparency were not affected by the supplementation. Facial skin imperfections were significantly reduced after the antioxidant-rich formulation intake (global reduction: $-18.0 \% ; P<0.0001$ ). Indeed, dark circles, redness, and spots significantly diminished after oral treatment. Firmness and elasticity have been shown to be improved. Subjects were globally satisfied by the product (82.4\%) and have found improvements on their facial skin. Furthermore, $64.7 \%$ reported to look better at the end of the supplementation.

Conclusion: The oral supplement containing the antioxidant-rich formulation was found to improve skin radiance by reducing skin coloring, increasing face luminosity, reducing imperfections, and improving skin firmness in women with dull complexion.

Keywords: antioxidants, skin radiance, oral supplement, aging, clinical trial

\section{Introduction}

Skin is the largest organ of the body and represents $16 \%$ of total body weight. It is a complex and multifunctional organ. Indeed, skin protects the body from the outside which means from physical, chemical, and infectious attacks and plays a role in several biological and biochemical processes. ${ }^{1}$

Visible skin appearance is an important moderator in human social interaction. It facilitates nonverbal communication. Humans attach great importance to a beautiful, 
healthy, and youthful-looking skin. Partly conveyed by the cosmetic industry, skin beauty includes a radiant complexion without imperfections. $^{2}$

There is no universal definition of skin radiance. The radiance of the complexion is multifactorial and it is difficult to list all the parameters that constitute it with their relative proportions..$^{3-5}$ The main characteristics are the skin contrast defined by the luminosity, brightness, and transparency; the skin color, mainly affected by the skin microcirculation; and the skin imperfections such as the homogeneity, dark circles, or spots. ${ }^{3,4,6}$

The skin radiance is influenced by intrinsic and extrinsic factors which can modulate skin aging. ${ }^{7-10}$ While the intrinsic aging is inevitable, extrinsic aging is the result of the interplay of external factors and human behaviors, such as tobacco, nutritional deficiencies, alcohol, stress, and ultraviolet (UV) exposure. Both of these factors impact the oxidative stress by an overproduction of reactive oxygen species. ${ }^{7,9,10}$ Thus, with aging, the skin is potentially more exposed to oxidative stress, leading to exacerbated reactive oxygen species production. ${ }^{11-13}$ This overproduction of free radicals, which plays an important role in skin aging, damages skin cells and in addition leads to a degradation of collagen and elastin. These fibers are responsible for the skin firmness and elasticity and the vessels integrity, and hence for the good skin vascularization. ${ }^{9,10,14}$ Moreover, cell degradation and UV exposure will lead to a heterogeneous overproduction of melanin by melanocytes, which leads to facial spots and a heterogeneous complexion. ${ }^{15}$

As the first line of cell defense against oxidative stress, primary antioxidants correspond to the endogenous system comprised of the only three antioxidant enzymes of the body: superoxide dismutase (SOD), catalase, and glutathione peroxidase. These enzymes contain trace elements in their active sites, such as copper, zinc, and selenium, supplied by food and essential for their enzymatic activity. ${ }^{16}$

To avoid such cellular damages, a reduction of the amount of secondary oxidants is the complementary step to lower the oxidative stress. This occurs firstly by enhancing the synthesis of primary antioxidants and secondly by lowering their spreading thanks to secondary antioxidants. Secondary antioxidants, as the second level of antioxidant protection, also called scavengers, correspond to exogenous substances, including hydrosoluble antioxidants (vitamin C, glutathione, and polyphenols) and liposoluble antioxidants (vitamin E, carotenoids, and bilirubin), which allow the diminution of the amplification loop of skin cell damage. ${ }^{11}$
Thus, nutrition and particularly dietary antioxidant active ingredients could help to protect skin from aging. First, they can act against the oxidative stress and secondly some of them are able to impact specific biological mechanisms enhancing the skin protection and repair.

The main objective of this study was to evaluate the effect of an 8-week oral supplementation with a formulation rich in specific antioxidants on skin radiance in healthy women with dull complexion.

\section{Materials and methods Subjects and product}

The clinical trial was conducted as an open-label, single-center study, approved by the Ethics Committee (Comite de Protection des Personnes Est-II, Besançon, France), complying with Good Clinical Practices in Human Beings, involving 35 female subjects aged between 40 and 70 years old, with a dull complexion evaluated by clinical scoring, phototypes II to IV on the Fitzpatrick scale, without a history of allergy or hypersensitivity to the products or one of their components. After having signed a written informed consent, the subjects were first checked for inclusion and exclusion criteria: eating habits (stable before and during the study); no concomitant treatment; no history of skin disease or treatment; no facial skin care (peeling, mask, and so on) during the study and 15 days before the beginning of the study; smoking habits (nonsmoking or $<5$ cigarettes per day); no UV exposure during the study; not pregnant, nursing, or intending to be pregnant in the course of the study; and use of oral nutritional supplements and/or vitamin supplementation (not $<1$ month before inclusion and not during the study).

A first assessment was performed in order to determine a baseline for each parameter (T0). Subjects then started daily oral use of SkinA ${ }^{2 \mathrm{TM}}$ (Activ'Inside, Libourne, France), a patent pending formulation containing grape seed extract, especially rich in flavanol monomers, a melon concentrate providing an SOD activity, zinc, and vitamin C, in a single intake of $150 \mathrm{mg}$ capsule for 8 weeks (from October to December 2014). A last assessment was performed at the end of the supplementation (T8) in order to compare the parameter values with the baseline.

\section{Clinical assessment}

Measurements were carried out on face skin which had received no application of product or makeup since the evening before the date of the visit as well as on the day of the visit. Before each assessment, volunteers were asked to remain in the examination room (airconditioned room, temperatureand hygrometry-controlled: $22^{\circ} \mathrm{C} \pm 2{ }^{\circ} \mathrm{C} ; 50 \% \pm 10 \% \mathrm{RH}$ ) for 
15 minutes in order to be in stable conditions of blood flow and skin temperature. All the descriptors have been evaluated by a unique trained assessor.

\section{Skin radiance assessment}

The main criterion was skin radiance evaluated by clinical scoring using the coloring, luminosity, brightness, and transparency (C.L.B.T. $\left.{ }^{\mathrm{TM}}\right)^{17}$ scale and imperfections scale (dark circles, redness/rosacea, spots, and heterogeneity).

The C.L.B.T. ${ }^{\mathrm{TM}}$ methodology allows assessing different descriptors of the complexion: coloring, luminosity, brightness, and transparency of facial skin. The descriptors have been defined precisely to ensure the homogeneity of the measurements. To determine the coloring, the following descriptors have been used: "red pink," "olive," and "beige." These descriptors have been evaluated visually based on structured visual color scales for the three hues (from $0 \%$ to $100 \%$ color saturation). Optimal values for each color have been interpreted as follows: red pink should decrease to diminish the red skin aspect, olive should decrease to diminish the sallow complexion, and beige should tend to medium as a clear complexion (Table 1).

Skin luminosity is defined as the intensity of the light areas reflected on the prominent areas of the face. Skin

Table I Clinical descriptors evaluated by C.L.B.T. ${ }^{\mathrm{TM}}$ and imperfections scale

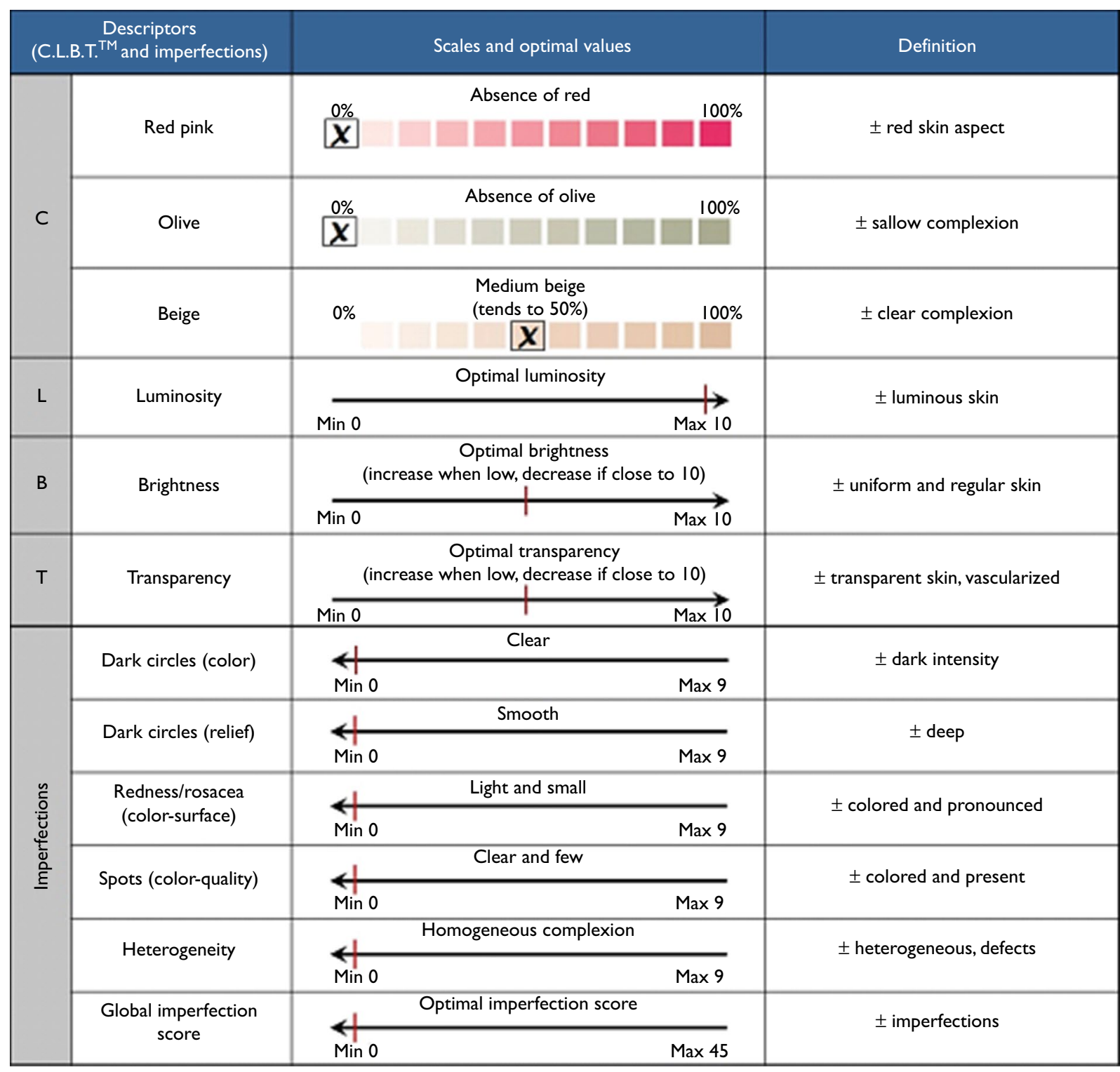

Abbreviations: C.L.B.T., coloring, luminosity, brightness, and transparency; Min, minimum; Max, maximum. 
brightness corresponds to the uniformity of the skin in terms of coloring and texture. Skin transparency is the possibility of seeing the vessels beneath the skin reflecting the level of vascularization and the skin thickness. The evaluation of luminosity, brightness, and transparency has been performed visually using a scale ranging the parameters from "no intensity" (limit 0) to "maximum" (limit 10). In this way, L.B.T. parameters have been interpreted as follows: luminosity should increase (from dark skin to luminous skin); brightness should increase, when low, to have a more uniform and regular skin, or should decrease, when high, to have a balanced shiny skin; and transparency should increase if low to have a more transparent skin, thinner, and well vascularized or should decrease when high to avoid seeing too many vessels under the skin (Table 1).

Facial skin imperfections have been evaluated through a clinical scoring reporting the color and relief of dark circles, redness/rosacea (color and surface), presence of spots (color and quantity), and heterogeneity of the skin imperfections. These criteria have been classed from 0 (absence or low) to 9 (very). Then, a global imperfection score has been calculated summing these five parameters ( 0 to 45 ) (Table 1$)$.

\section{Skin firmness and elasticity assessment}

Skin firmness and elasticity have been evaluated respectively with a clinical evaluation and a Cutometer SM575 (Courage-Khazaka Electronic, Köln, Germany). The firmness evaluation was scored from "Absent/Light" to "Moderate/ Important" by an examiner. The cutometer measures the elasticity of the skin in vivo by a suction test. A probe of 6 $\mathrm{mm}$ diameter is applied to the skin and a temporary vacuum is created (400 mbars), thus deforming the skin (on time: 3 seconds; off time: 2 seconds; repetition: 5). Adhesive tape is attached to the probe and prevents the adjacent skin from being sucked into the chamber. The device holds a spring ensuring a constant application pressure $\left(50 \mathrm{~g} / \mathrm{cm}^{2}\right)$. An optical system made of a light source and a receptor determines the skin deformation and its slackness. Different parameters are measured: immediate deformation Ue (U extensibility), delayed deformation Uv (U viscous), final deformation Uf $(\mathrm{Uf}=\mathrm{Ue}+\mathrm{Uv})$, and deformation of immediate retraction $\mathrm{Ur}$, when the vacuum is removed. The ratio Ur/Ue characterizes the elasticity of the skin and is independent of the thickness of the skin. ${ }^{18}$

\section{Self-assessment of skin parameters}

As the perception of the skin radiance is subjective, a selfassessment has been performed through a questionnaire. Ten different questions were asked.
Eight were answered at T0 and T8: "For you, the radiance of your complexion is?" from $0=$ dull to $10=$ glowing; "Is your complexion fresh?" from $0=$ not to $10=$ very; "Is your complexion luminous?" from $0=$ not to $10=$ very; "Is your complexion homogeneous?" from $0=$ not to $10=$ very; "Is your skin smooth?" from $0=$ not to $10=$ very; "Is your skin texture refined?" from $0=$ not to $10=$ very; "Is your skin firm?" from $0=$ soft to $10=$ firm; and "Is your skin hydrated?" from $0=$ not to $10=$ very.

Two satisfaction questions were asked at T8 only: "Do you think you look better?" yes or no; and "How do you estimate the global efficacy of the dietary supplement?" $0=$ none, $1=$ moderate, $2=$ good, and $3=$ very good.

The tolerance of the product has been evaluated by spontaneous comments and/or clinical observations.

\section{Statistical analyses}

Statistical analyses have been realized using StatView ${ }^{\circledR}$ software (SAS Institute Inc., Cary, NC USA). Graphical representations were performed using GraphPad Prism ${ }^{\circledR}$ (GraphPad Software, Inc., La Jolla, CA, USA). The difference between $\mathrm{T} 0$ and $\mathrm{T} 8$ has been tested using Student's paired $t$-test or Wilcoxon Signed-Rank Test according to the normality assumption of data distribution (Kolmogorov-Smirnov test). The firmness score has been analyzed using chi-square test.

\section{Results \\ Effects of the supplementation on the C.L.B.T. ${ }^{\mathrm{TM}}$ parameters}

C.L.B.T. ${ }^{\mathrm{TM}}$ parameters have been scored by an examiner at $\mathrm{T} 0$ and T8. Concerning the color parameters, statistical analyses revealed a significant decrease of the saturation for the red pink color $(-34.8 \%$ vs T0; $P<0.0001)$ and the olive color $(-21.6 \%$ vs T0; $P<0.0001)$ between T0 and T8. However, no significant effect has been observed for the beige color which only changed from $6.5 \%$ to $9.1 \%$ (absolute values) in deviation from the optimal value of $50 \%(P=0.1069)$ (Figure 1A). Analyses have also shown that the luminosity was significantly increased after 8 weeks of supplementation $(+25.9 \%$ vs T0; $P<0.0001$ ) (Figure 1B). On the contrary, brightness has been observed to decrease from T0 to T8 by $12.3 \%(P<0.05)$ (Figure 1C). Finally, no significant change has been observed for the transparency $(+7.9 \% ; P=0.238)$ (Figure 1D).

\section{Effects of the supplementation on skin imperfections}

Significant improvements have been observed at study end on the imperfection parameters measured. Dark circles have 

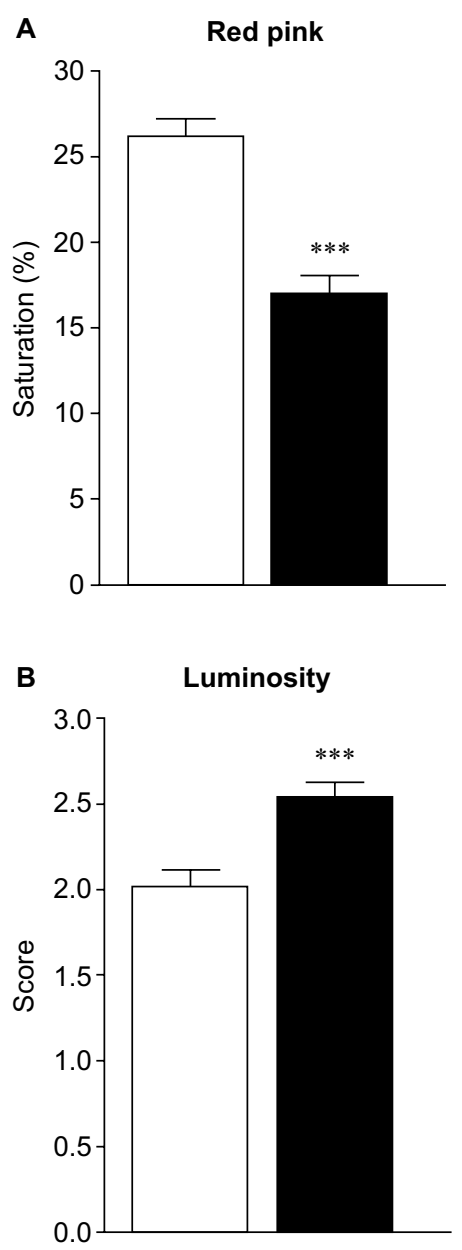
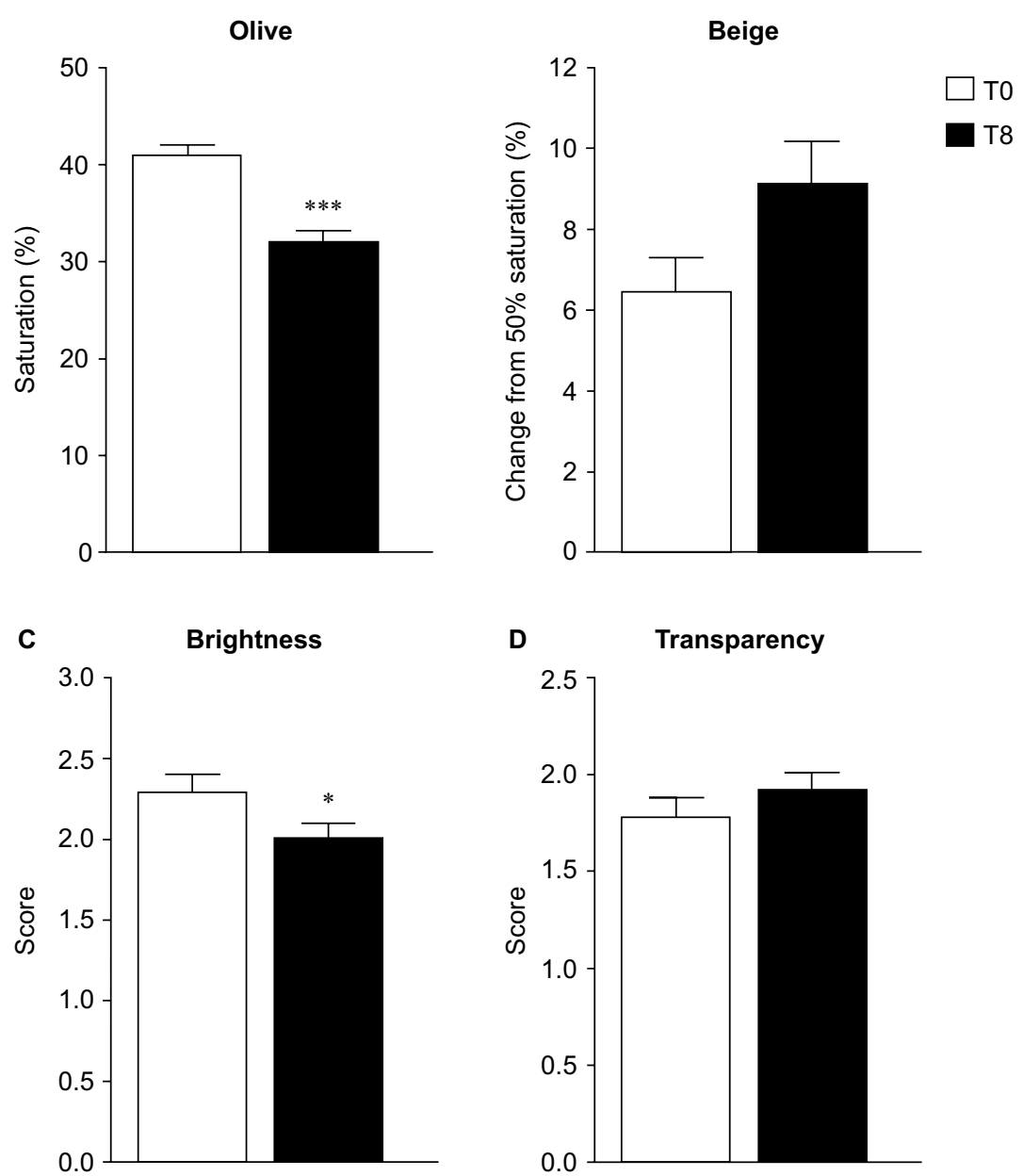

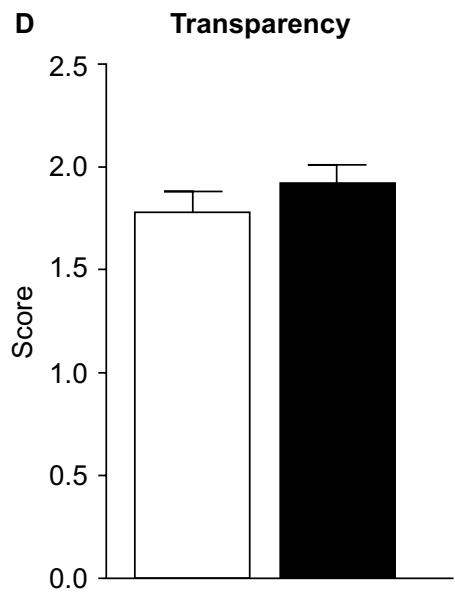

Figure I Evaluation of the C.L.B.T. ${ }^{\mathrm{TM}}$ parameters before and after supplementation.

Notes: (A) Red pink and olive color decrease significantly $(* * * P<0.000 \mathrm{I})$. Beige color is not significantly altered as the change of deviation from the optimal value 50 is not modified after the supplementation. (B) Luminosity is significantly increased at the end of the supplementation compared to the baseline ( $* * * P<0.000 \mathrm{I})$. (C) Brightness decreases at $\mathrm{T} 8$ compared to the baseline $\left({ }^{*} P<0.05\right)$. (D) Transparency increases slightly but not significantly at T8.

Abbreviations: C.L.B.T., coloring, luminosity, brightness, and transparency; T0, Time 0, baseline; T8, Time 8, eight weeks.

been shown to be reduced in both relief $(-11.7 \%$ vs $\mathrm{T} 0$; $P<0.01)$ and color $(-19.2 \%$ vs T0; $P<0.0001)$ (Figure $2 \mathrm{~A})$.

Redness/rosacea (color and surface) has also been reduced after supplementation $(-19.3 \%$ vs T0; $P<0.0001)$ as well as the spots (color and quantity) $(-20.7 \%$ vs T0; $P<0.0001)$ (Figure 2B and C). However, heterogeneity of the skin has not been significantly modified $(-1.7 \%$ vs T0; $P=0.2850)$ (Figure 2D). The global score of imperfection (dark circles relief and color, redness/rosacea, spots, and heterogeneity) has thus been significantly reduced after the supplementation as revealed by the decrease of $18.0 \%$ compared to the baseline (T0) value for this global score $(P<0.0001)$ (Figure 2E).

\section{Effects of the supplementation on the firmness and the elasticity of the skin}

First, an evaluation of the skin firmness has been realized by an examiner. Skin firmness was classified as Absent-Light firmness or Moderate-Important firmness. A chi-square analysis revealed a significant change from the Absent-Light category to the Moderate-Important category of firmness after the supplementation (chi-square $=4.121 ; P<0.05)$ (Table 2).

Elasticity has been evaluated with a cutometer. A significant increase of elasticity (Ur/Ue) has been measured $(+8.53 \%$ vs T0; $P<0.05)$ (Figure 3$)$.

\section{Auto-evaluation and satisfaction of women}

Women subjects were asked to answer an auto-questionnaire. As observed in Table 3, from baseline to the end of the supplementation, they found their skin more radiant $(+28.9 \%$; $P<0.01)$, fresher $(+35.9 \% ; P<0.0001)$, more luminous $(+30.6 \% ; P<0.01)$, more homogeneous $(+37.2 \% ; P<0.01)$, smoother $(+18.7 \% ; P<0.05)$, and firmer $(+19.5 \% ; P<0.05)$. However, they did not see a significant improvement of the skin texture or of its hydration. The proportion of the total 


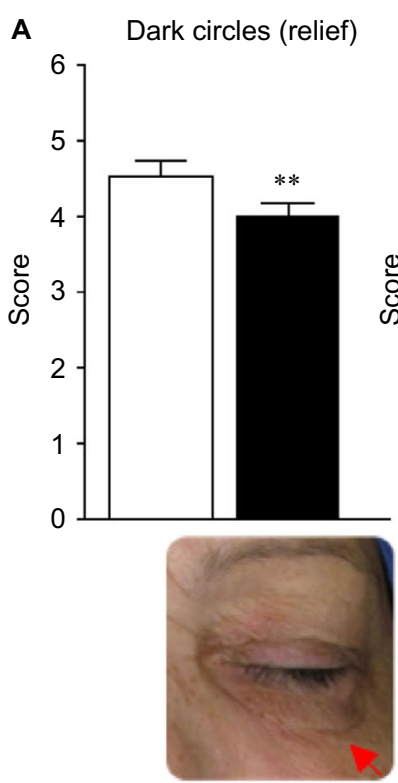

TO

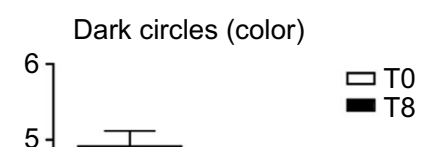

C

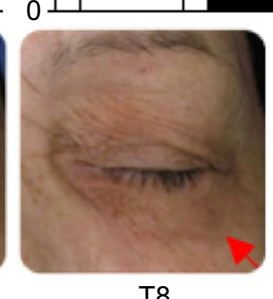

T8

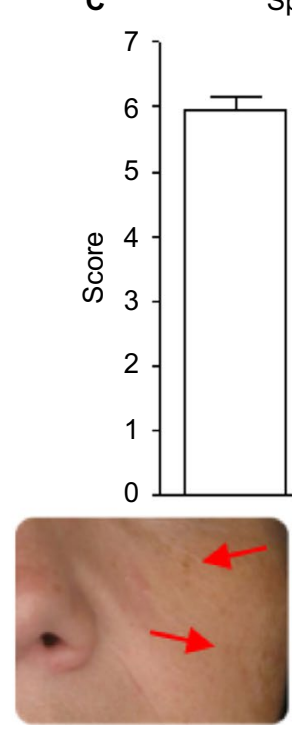

Spots

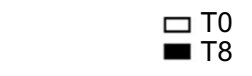

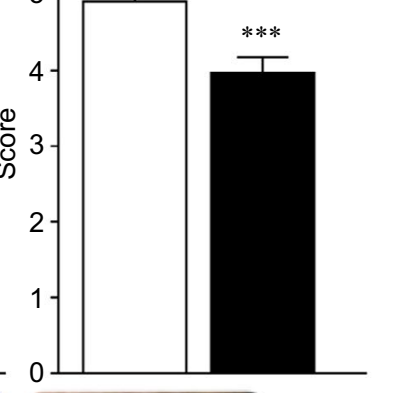

T0
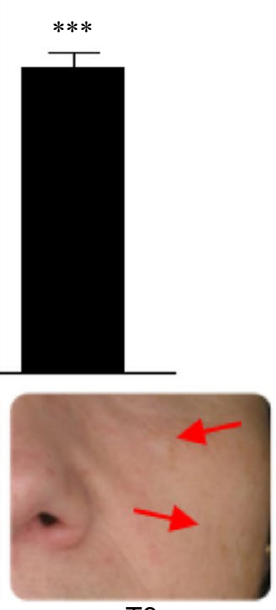

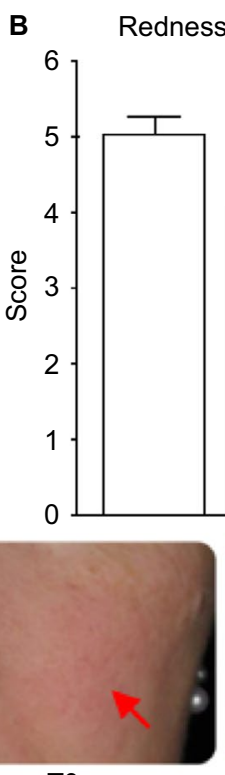

T0

Heterogeneity
E Imperfection score \%

D

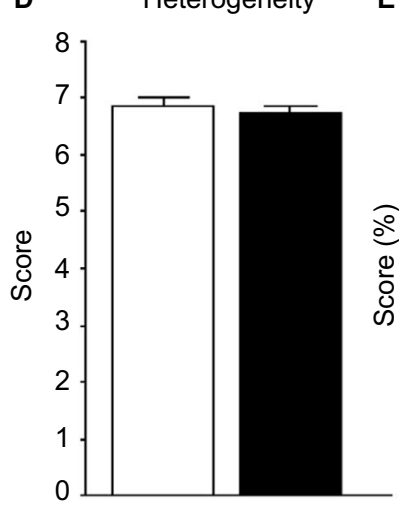

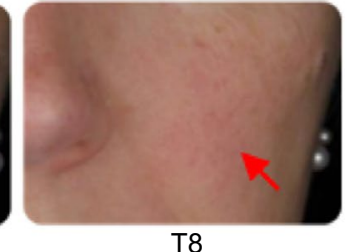

T8

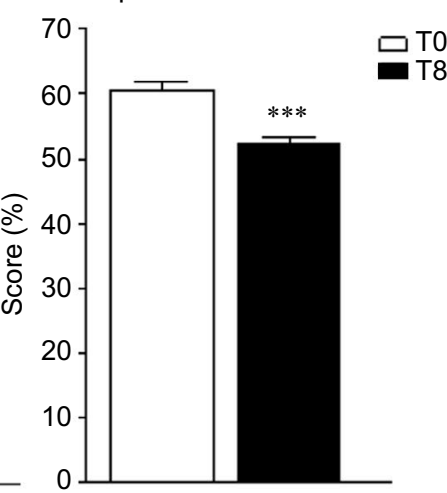

Figure 2 Evaluation of the facial skin imperfections before and after supplementation.

Notes: (A) Dark circles relief and color are reduced after supplementation compared to baseline ( $* * P<0.01$; $* * * P<0.000 \mathrm{I})$, (B) redness is also reduced at T8 compared to baseline T0 (***P<0.000I), and (C) spots are decreased after supplementation ( $* * * P<0.000 \mathrm{I})$. (D) Complexion heterogeneity is not modified by the supplementation. (E) The global imperfection score (dark circles relief and color + redness/rosacea + spots + heterogeneity scores) decreased by $18 \%(* * * P<0.0001)$.

Abbreviations: T0, Time 0, baseline; T8, Time 8, eight weeks.

Table 2 Firmness evaluation by clinical examination

\begin{tabular}{lllllll}
\hline Firmness & T0 & & \multicolumn{2}{c}{ T8* } \\
\cline { 2 - 3 } \cline { 5 - 6 } & $\mathbf{n}$ & & & $\mathbf{n}$ & $\%$ \\
\hline Absent-Light & 16 & & & & \\
Moderate-Important & 18 & & & 8 & 23.5 \\
\hline
\end{tabular}

Note: Population repartition was significantly different between T0 and T8 switching from the "Absent-Light" to the "Moderate-Important" category of firmness $\left({ }^{*} P<0.05\right)$. Abbreviations: T0, Time 0, baseline; T8, Time 8, eight weeks.

numbers of women seeing an improvement has also been calculated revealing that the majority of the population observed a positive evolution of these parameters. Moreover, this positive evolution is globally important, ranging from $+37.7 \%$ for the skin grain to $101.1 \%$ for the homogeneous complexion (Table 3 ).

When women were asked if they looked better after the supplementation, $64.7 \%$ answered yes. In parallel, $82.4 \%$ of the subjects answered that they were satisfied by the efficacy of the supplement (from moderate to very good) (Table 4).

The tolerance of the product was considered as safe because no serious adverse events occurred during the study. 


\section{Discussion}

According to several authors, the skin radiance appears to be the combination of the light reflection within the skin (luminosity and brightness), level of skin imperfections, and skin color. ${ }^{3,4,6}$ Complemented by appropriate techniques, sensory evaluation seems to be a good method to appreciate skin radiance as a whole.

The skin aging process is influenced by genetic and environmental factors with consequent impact on the oxidative

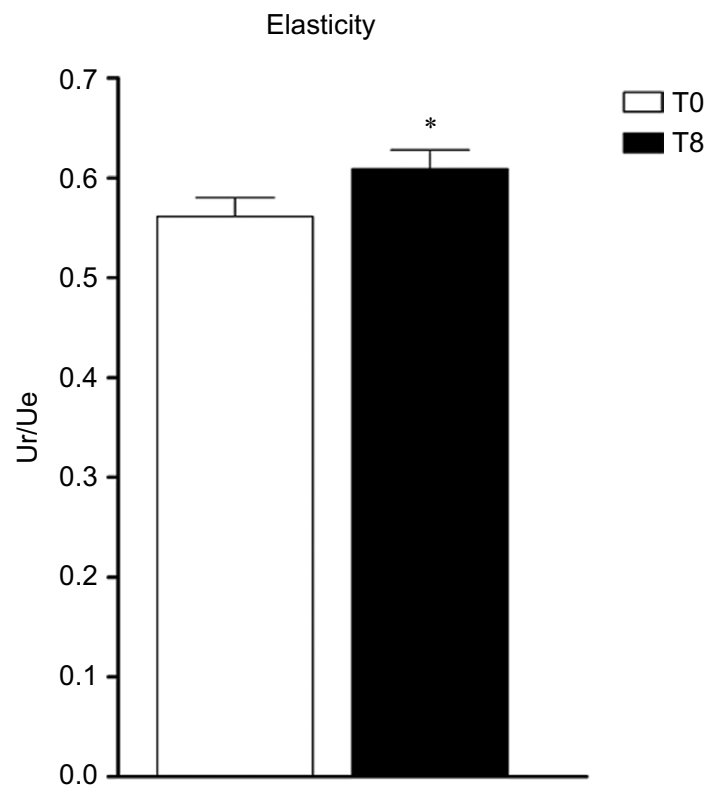

Figure 3 Evaluation of the skin elasticity by cutometer.

Note: Elasticity, represented by the ratio Ur/Ue, increases reflecting a better skin elasticity $(* P<0.05)$

Abbreviations: $\cup e, U$ extensibility; $U r$, immediate retraction; T0, Time 0 , baseline; T8, Time 8, eight weeks. stress. The production of free radicals leads to the deterioration of cellular structures, lipids, DNA, and proteins. At the skin level, one of the main consequences is the degradation of collagen and elastin. ${ }^{7-10}$ These fibers are responsible for the skin firmness and elasticity. Moreover, they play an important role in the vessels integrity and thus in the skin vascularization. ${ }^{9,10,14}$ Furthermore, cell degradation and UV exposure results in a heterogeneous overproduction of melanin by melanocytes, which can cause the appearance of facial spots and a heterogeneous complexion. ${ }^{15}$

Our results suggest a positive effect of oral supplementation rich in primary and secondary antioxidants on skin radiance. Skin color, facial luminosity, and firmness have been improved and imperfections reduced. As oxidative stress actively impacts skin aging, the scavenger effect of antioxidant-rich formulation components seems to be relevant to protect skin.

Above all, the dietary formulation has been specially developed to protect skin against the oxidative stress by using different antioxidants, primarily with the SOD, and

Table 4 Auto-evaluation after the supplementation: satisfaction questions

\begin{tabular}{lll}
\hline Satisfaction questions & & \\
\hline Do you think you look better? & No & Yes \\
& $35.3 \%(n=12)$ & $\begin{array}{l}64.7 \%(n=22) \\
\text { Moderate to }\end{array}$ \\
How do you estimate the & None & $\begin{array}{l}\text { very good } \\
\text { global efficacy of the dietary }\end{array}$ \\
$\begin{array}{l}\text { supplement? } \\
\text { I7.6\% }(n=6)\end{array}$ & $82.4 \%(n=28)$ \\
\hline
\end{tabular}

Table 3 Auto-evaluation of skin parameters at T0 and T8

\begin{tabular}{|c|c|c|c|c|c|c|c|}
\hline Questions & TO & T8 & & $\begin{array}{l}\text {-value } \\
\text { (T8 vs T0) }\end{array}$ & $\begin{array}{l}\text { Evolution } \\
\text { (\%) }\end{array}$ & $\begin{array}{l}\text { Women } \\
\text { with positive } \\
\text { evolution (\%) }\end{array}$ & $\begin{array}{l}\text { Evolution in } \\
\text { women with } \\
\text { positive score (\%) }\end{array}$ \\
\hline $\begin{array}{l}\text { For you, the radiance of your complexion is? } \\
(0=\text { dull }->10=\text { glowing })\end{array}$ & $4.0 \pm 0.3$ & $5.1 \pm 0.3$ & $* *$ & $<0.01$ & 28.9 & 76.5 & 62.3 \\
\hline $\begin{array}{l}\text { Is your complexion fresh? } \\
(0=\text { not }->10=\text { very })\end{array}$ & $3.9 \pm 0.2$ & $5.3 \pm 0.3$ & $* * *$ & $<0.0001$ & 35.9 & 79.4 & 52.6 \\
\hline $\begin{array}{l}\text { Is your complexion luminous? } \\
(0=\text { not }->10=\text { very })\end{array}$ & $3.8 \pm 0.3$ & $5.0 \pm 0.3$ & $* *$ & $<0.01$ & 30.6 & 70.6 & 69.4 \\
\hline $\begin{array}{l}\text { Is your complexion homogeneous? } \\
(0=\text { not }->10=\text { very })\end{array}$ & $3.2 \pm 0.4$ & $4.3 \pm 0.4$ & $* *$ & $<0.01$ & 37.2 & 67.6 & 101.0 \\
\hline $\begin{array}{l}\text { Is your skin smooth? } \\
(0=\text { not }->10=\text { very })\end{array}$ & $4.4 \pm 0.4$ & $5.2 \pm 0.3$ & $*$ & $<0.05$ & 18.7 & 61.8 & 52.3 \\
\hline $\begin{array}{l}\text { Is your skin texture refined? } \\
(0=\text { not refined }->10=\text { very refined })\end{array}$ & $4.7 \pm 0.4$ & $5.2 \pm 0.3$ & NS & 0.1598 & 8.7 & 66.7 & 37.7 \\
\hline $\begin{array}{l}\text { Is your skin firm? } \\
(0=\text { soft }->10=\text { firm })\end{array}$ & $3.7 \pm 0.3$ & $4.4 \pm 0.3$ & $*$ & $<0.05$ & 19.5 & 67.6 & 55.8 \\
\hline $\begin{array}{l}\text { Is your skin hydrated? } \\
(0=\text { not }->10=\text { very })\end{array}$ & $4.4 \pm 0.3$ & $4.8 \pm 0.3$ & NS & 0.2365 & 9.6 & 58.8 & 45.9 \\
\hline
\end{tabular}

Notes: $* P<0.05 ; * * P<0.01 ; * * * P<0.001$.

Abbreviations: NS, not significant; T0, Time 0, baseline; T8, Time 8, eight weeks. 
secondarily with the flavanol monomers from grape, vitamin C, and zinc. ${ }^{16,19,20}$ Monomers of flavanols have been chosen instead of polymers because they are more bioavailable. Indeed, studies have shown that flavanol polymerization limits absorption in the gut. ${ }^{21,22}$ Furthermore, a potential synergistic effect between vitamin $\mathrm{C}$ (ascorbic acid) and flavanol monomers has been demonstrated in vitro and in vivo. This synergistic effect has been observed on antioxidant capacities with catechin alone or in the presence of ascorbic acid. ${ }^{23}$ The authors suggested that the higher radical-scavenging ability can be due to a regeneration process of catechin radical by ascorbic acid. Another synergistic potential has been confirmed in vivo where it has been shown that flavanols improved the vitamin $\mathrm{C}$ bioavailability. ${ }^{24}$

The improvement of the firmness and the elasticity suggests that elastic fibers have been protected by the supplementation. Indeed, the firmness of the skin is mainly linked to collagen and elastin, which confer stability to the dermis and its elastic properties. ${ }^{9}$ Furthermore, improvement of skin firmness also allows reduction of dark circles. The generation of reactive oxygen species, in particular by UV radiation, induces the production of collagenase and elastase, responsible for collagen and elastin degradation. Vitamin C stimulates collagen synthesis, acting as a cofactor in the hydroxylation of proline and lysine, essential amino acids in the formation of collagen fibers. ${ }^{25,26}$ Flavanols, and in particular monomers, inhibit the degradation of collagen and elastin by fixation on fibers, which reduce the action of collagenase and elastase. Moreover, flavanols are known to stimulate the synthesis of amino acids precursors of collagen and elastin. ${ }^{27-38}$

This action on skin elastic fibers has a direct impact on the vascularization system acting on the capillary resistance. This effect on skin circulation has been observed through the skin color improvement after supplementation as the main pigments responsible for the different hues are melanin, bilirubin, and hemoglobin. ${ }^{17}$ The reductions of redness/ rosacea and dark circles color are linked with these impacts on vascularization. Moreover, the vascularization improvement is also possible through the vasodilation and blood flow. First, it allows improving the nutrient circulation, and it is important for the bioavailability of the product. Blood flow also participates in the skin hydration. Thus, flavanol monomers from grape and SOD are known to improve the vasodilation increasing the nitroso species production. ${ }^{39-44}$

A regulation of the age-related heterogeneous overproduction of melanin has been observed in particular with the reduction of facial spots. The improvement of skin color also reflects this impact as one of the main pigments responsible for skin hue is the melanin. ${ }^{17}$ Flavanol monomers and vitamin
$\mathrm{C}$ are known to reduce the tyrosinase activity necessary for the melanogenesis and, thus, they are able to regulate the melanin synthesis. ${ }^{15,45-47}$

The term "radiance" often refers to the shining and lightening aspect. Interestingly, in our study, luminosity, linking with the global skin color and skin homogeneity, was improved. However, a radiant complexion seems to be associated with several skin characteristics reflecting the physical and psychological health.,48 Thus, radiance evaluation remains at least in part subjective. The final auto-assessment of several parameters involved in skin radiance contributes to bringing more information concerning the effects of the oral supplementation. Tested women were satisfied concerning different specific points, such as their skin radiance, skin luminosity, or its hydration. They were also globally satisfied by the product, up to $82.4 \%$. Finally, they felt they looked better after the supplementation.

This study brings positive arguments in favor of an oral supplementation with a formulation rich in specific antioxidants to protect skin from the environmental daily damage and intrinsic aging. However, further investigation with complementary methods could bring more information concerning the potential of the product. In particular, the lack of a control group and relatively small population size limit the conclusions that can be drawn about the efficacy of this product.

\section{Conclusion}

The clinical study results suggest that daily oral supplementation with an antioxidant-rich formulation, which contains a melon concentrate providing an SOD activity, grape seed extract rich in monomers of flavanols, vitamin $\mathrm{C}$, and zinc, has a beneficial effect on skin radiance (improvement of luminosity, reduction of imperfections, and improvement of skin firmness) in women.

\section{Disclosure}

This study was sponsored by Activ'Inside. Activ'Inside is the supplier of SkinAx ${ }^{2 \mathrm{TM}}$. The authors report no other conflicts of interest in this work.

\section{References}

1. Venus M, Waterman J, McNab I. Basic physiology of the skin. Surgery. 2011;29(10):471-474.

2. Samson N, Fink B, Matts PJ. Visible skin condition and perception of human facial appearance. Int J Cosmet Sci. 2010;32(3):167-184.

3. Baret M, Bensimon N, Coronel S, Ventura S, Nicolas-Garcia S, Korichi $\mathrm{R}$, Gazano G. Characterization and quantification of the skin radiance through new digital image analysis. Skin Res Technol. 2006;12(4): 254-260.

4. Petitjean A, Sainthillier JM, Mac-Mary S, Muret P, Closs B, Gharbi T, Humbert P. Skin radiance: how to quantify? Validation of an optical method. Skin Res Technol. 2007;13(1):2-8. 
5. Petitjean A, Ambruster V, Trolard B, et al. Approche optique de la caractérisation de l'éclat du teint. In: ESKA, ed. Actualités en ingénierie cutanée. Vol 42006:133-138.

6. Petitjean A. Approches biométrologiques de l'éclat du teint [Thèse doctorat: Sciences de la vie et de la santé]: Université de Franche Comté, Faculté de médecine et de pharmacie de Besançon; 2006.

7. Rocquet $\mathrm{C}$, Bonté $\mathrm{F}$. Molecular aspects of skin ageing: Recent data. Acta Dermatoven. 2002;11(3):71-94.

8. Marieb E. Anatomie et physiologie humaines. Edition du renouveau pédagogique ed: De Boeck Université, traduction de la 4ème édition américaine; 1999.

9. Mélissopoulos A, Levacher C. La Peau, structure et physiologie. 2e édition. ed: TEC\&DOC / Lavoisier; 2012.

10. Baumann L. Skin ageing and its treatment. JPathol. 2007;211(2):241-251.

11. Kohen R. Skin antioxidants: their role in aging and in oxidative stress - new approaches for their evaluation. Biomed Pharmacother. 1999;53(4):181-192.

12. Poljsak B, Dahmane R. Free Radicals and Extrinsic Skin Aging. Dermatol Res Prat. 2012:135206.

13. Valko M, Leibfritz D, Moncol J, Cronin MT, Mazur M, Telser J. Free radicals and antioxidants in normal physiological functions and human disease. Int J Biochem Cell Biol. 2007;39(1):44-84.

14. Choung BY, Byun SJ, Suh JG, Kim TY. Extracellular superoxide dismutase tissue distribution and the patterns of superoxide dismutase mRNA expression following ultraviolet irradiation on mouse skin. Exp Dermatol. 2004;13(11):691-699.

15. Yamakoshi J, Sano A, Tokutake S, et al. Oral intake of proanthocyanidin-rich extract from grape seeds improves chloasma. Phytother Res. 2004;18(11):895-899.

16. Droge W. Free radicals in the physiological control of cell function. Physiol Rev. 2002;82(1):47-95.

17. Musnier C, Piquemal P, Beau P, Pittet JC. Visual evaluation in vivo of 'complexion radiance' using the C.L.B.T. sensory methodology. Skin Res Technol. 2004;10(1):50-56.

18. Hacard F, Machet L, Caille A, et al. Measurement of skin thickness and skin elasticity to evaluate the effectiveness of intensive decongestive treatment in patients with lymphoedema: a prospective study. Skin Res Technol. 2014;20(3):274-281.

19. Afonso V, Champy R, Mitrovic D, Collin P, Lomri A. Reactive oxygen species and superoxide dismutases: role in joint diseases. Joint Bone Spine. 2007;74(4):324-329.

20. Kwon M-J, Kim B, Lee YS, Kim T-Y. Role of superoxide dismutase 3 in skin inflammation. J Dermatol Sci. 2012;67(2):81-87.

21. Déprez S, Mila I, Huneau J-F, Tomé D, Scalbert A. Transport of proanthocyanidin dimer, trimer and polymer across monolayers of human intestinal epithelial Caco-2 cells. Antiox Redox Signal. 2001;3(6):957-967.

22. Gonthier M-P, Donovan JL, Texier O, Felgines C, Remesy C, Scalbert A. Metabolism of dietary procyanidins in rats. Free Radic Biol Med. 2003;35(8):837-844.

23. de Souza RF, De Giovani WF. Antioxidant properties of complexes of flavonoids with metal ions. Redox Rep. 2004;9(2):97-104.

24. Schwitters B, Masquelier J. Vitamin C and OPC, immortal twins. OPC in practice: the hidden story of proanthocyanidins, nature's most powerful and patented antioxydant: Alfa Omega ed; 1995:70-73.

25. Kishimoto Y, Saito N, Kurita K, Shimokado K, Maruyama N, Ishigami A. Ascorbic acid enhances the expression of type 1 and type 4 collagen and SVCT2 in cultured human skin fibroblasts. Biochem Biophys Res Commun. 2013;430(2):579-584

26. Derricks KE, Rich CB, Buczek-Thomas JA, Nugent MA. Ascorbate enhances elastin synthesis in $3 \mathrm{D}$ tissue-engineered pulmonary fibroblasts constructs. Tissue Cell. 2013;45(4):253-260.

27. Delorme-Prieur C. Carastérisation chimique des procyanidols de pépins de raisin Vitis vinifera. Application à l'étude des propriétés organoleptiques des vins [Sciences]. Montpellier: Sciences et techniques du Languedoc, Université de Montpellier II; 1994.
28. Hagerman AE, Butler LG. The specificity of proanthocyanidin-protein interactions. J Biol Chem. 1981;256(9):4494-4497.

29. Masquelier J. A lifetime devoted to OPC and Pycnogenols. Alfa Omega Editice; 1996.

30. Haslam E. Polyphenol-protein interactions. Biochem J. 1974;139(1): 285-288.

31. Drubaix I, Viljanen-Tarifa E, Robert A, Robert L. [Role of glycosoaminoglycans in venous disease. Mode of action of some flavonoid drugs]. Pathol Biol (Paris). 1995;43(5):461-470.

32. Maffei Facino R, Carini M, Aldini G, Bombardelli E, Morazzoni P, Morelli R. Free radicals scavenging action and anti-enzyme activities of procyanidines from Vitis vinifera. A mechanism for their capillary protective action. Arzneimittelforschung. 1994;44(5):592-601.

33. Masquelier J. Oligomères procyanidoliques. Parfums, cosmétiques, arômes. 1990;95:89-97. French.

34. Masquelier J, Dumon M, Dumas J. Stabilisation du collagène par les oligomères procyanidoliques. Acta Therapeutica. 1981;7:101-105. French.

35. Tixier J, Godeau G, Robert A, Hornebeck W. Evidence by in vivo and in vitro studies that binding of pycnogenols to elastin affects its rate of degradation by elastases. Biochem Pharmacol. 1984;33(24): 3933-3939.

36. Madhan B, Krishnamoorthy G, Rao J, Nair B. Role of green tea polyphenols in the inhibition of collagenolytic activity by collagenase. Int J Biol Macromolec. 2007;41(1):16-22.

37. Kuttan R, Donnelly PV, Di Ferrante N. Collagen treated with (+)-catechin becomes resistant to the action of mammalian collagenase. Experientia. 1981;37(3):221-223.

38. Gavignet-Jeannin C, Groult N, Godeau G, Robert A, Robert L. Mode d'action des oligomères procyanidoliques sur la paroi vasculaire. Paper presented at: Congrès international d'angiologie de Toulouse; 4-7 octobre, 1988; Toulouse.

39. Jung O, Marklund SL, Geiger H, Pedrazzini T, Busse R, Brandes RP. Extracellular superoxide dismutase is a major determinant of nitric oxide bioavailability: in vivo and ex vivo evidence from ecSOD-deficient mice. Circ Res. 2003;93(7):622-629.

40. Barona J, Aristizabal JC, Blesso CN, Volek JS, Fernandez ML. Grape polyphenols reduce blood pressure and increase flow-mediated vasodilation in men with metabolic syndrome. J Nutr. 2012;142(9): 1626-1632.

41. Barona J, Blesso CN, Andersen CJ, Park Y, Lee J, Fernandez ML. Grape consumption increases anti-inflammatory markers and upregulates peripheral nitric oxide synthase in the absence of dyslipidemias in men with metabolic syndrome. Nutrients. 2012;4(12):1945-1957.

42. Sivaprakasapillai B, Edirisinghe I, Randolph J, Steinberg F, Kappagoda T. Effect of grape seed extract on blood pressure in subjects with the metabolic syndrome. Metabolism. 2009;58(12):1743-1746.

43. Chaves AA, Joshi MS, Coyle CM, et al. Vasoprotective endothelial effects of a standardized grape product in humans. Vascul Pharmacol. 2009;50(1-2):20-26.

44. Hooper L, Kay C, Abdelhamid A, Kroon PA, Cohn JS, Rimm EB, Cassidy A. Effects of chocolate, cocoa, and flavan-3-ols on cardiovascular health: a systematic review and meta-analysis of randomized trials. Am J Clin Nutr. 2012;95(3):740-751.

45. Yamakoshi J, Otsuka F, Sano A, Tokutake S, Saito M, Kikuchi M, Kubota Y. Lightening effect on ultraviolet-induced pigmentation of guinea pig skin by oral administration of a proanthocyanidin-rich extract from grape seeds. Pigment Cell Res. 2003;16(6):629-638.

46. Shimada Y, Tai H, Tanaka A, Ikezawa-Suzuki I, Takagi K, Yoshida Y, Yoshie H. Effects of ascorbic acid on gingival melanin pigmentation in vitro and in vivo. J Periodontol. 2009;80(2):317-323.

47. Choi YK, Rho YK, Yoo KH, et al. Effects of vitamin C vs. multivitamin on melanogenesis: comparative study in vitro and in vivo. Int $J$ Dermatol. 2010;49(2):218-226.

48. Barel AO, Paye M, Maibach HI. Handbook of Cosmetic Science and Technology. 3rd ed. Taylor \& Francis; 2009. 


\section{Publish your work in this journal}

Clinical, Cosmetic and Investigational Dermatology is an international, peer-reviewed, open access, online journal that focuses on the latest clinical and experimental research in all aspects of skin disease and cosmetic interventions. This journal is included on PubMed. The manuscript management system is completely online

Submit your manuscript here: https://www.dovepress.com/clinical-cosmetic-and-investigational-dermatology-journal

and includes a very quick and fair peer-review system, which is all easy to use. Visit http://www.dovepress.com/testimonials.php to read real quotes from published authors 